\title{
Transcatheter aortic valve replacement
}

\author{
This article was published in the following Dove Press journal: \\ Research Reports in Clinical Cardiology \\ 5 August 2013 \\ Number of times this article has been viewed
}

\section{Anneke Damberg \\ Carina Benstoem \\ Ruediger Autschbach \\ Andreas Goetzenich}

Department of Cardiovascular and Thoracic Surgery, University Clinic RWTH Aachen, Aachen, Germany
Correspondence: Andreas Goetzenich Clinic for Cardiovascular and Thoracic Surgery, University Clinic Aachen, Pauwelsstr 30, 52074 Aachen, Germany Tel +4924I 8035556

Fax +49 24I 803335556

Email agoetzenich@ukaachen.de
Abstract: The standard treatment for symptomatic severe aortic valve stenosis is surgical aortic valve replacement. Over the last decade, transcatheter aortic valve replacement has emerged as an option for patients judged inoperable. It might also constitute an alternative for high-risk patients, even though which patients might benefit from this approach is still being discussed and remains controversial. Transcatheter heart valve replacement is a rapidly spreading technology. However, a number of problems still need to be addressed, such as paravalvular regurgitation, stroke rate, and postoperative conduction disturbances. Further, the durability of transcatheter heart valves remains unclear. Randomized clinical trials and long-term follow-up will help define the role of transcatheter heart valve replacement in aortic stenosis therapy.

Keywords: TAVI, aortic valve replacement, transcatheter surgery

\section{Introduction}

Aortic valve stenosis is the most common type of valvular heart disease. ${ }^{1}$ Its prevalence is known to increase with age; from $1.3 \%$ among the population aged $65-75$ to $4 \%$ in people aged over 85 years. ${ }^{2}$ Although patients with severe aortic valve stenosis can remain asymptomatic for a long period, 5 -year survival is only $15 \%-50 \%$ once the first symptoms have occurred. ${ }^{3}$ Surgical aortic valve replacement (SAVR) is indicated in symptomatic patients, as well as in some subgroups of patients who are still asymptomatic - for example, patients with reduced left-ventricular ejection fraction (LVEF) not due to another cause. ${ }^{3}$

In Europe, overall operative mortality for isolated aortic valve replacement (AVR) is 3\%, with strong age dependence: while mortality is $1.2 \%$ in patients younger than 56 years old, mortality reaches $6.1 \%$ in octogenarians. ${ }^{4}$ According to a contemporary European survey, ${ }^{1} 54.3 \%$ of patients undergoing surgery for aortic stenosis are aged over 70 years. Accordingly, surgery is declined to at least one-third of patients, mostly due to comorbidities and increased age. ${ }^{1}$

For a long time, medical therapy and balloon valvuloplasty were the only treatment options for patients deemed unsuitable for surgery. ${ }^{5}$ Over the last decade, transcatheter aortic valve replacement (TAVR) has emerged as a new option for inoperable and high-risk patients. In TAVR, a bioprosthetic valve within a stent is inserted into the aortic annulus, either retrogradely, via a femoral, subclavian, or direct aortic approach, or antegradely, via the left-ventricular apex. ${ }^{6}$ TAVR has been embedded in most international treatment guidelines during the last few years. ${ }^{3,7}$ While long-term results have yet to be reported, future clinical trials are aiming to expand the indication for TAVR to an intermediate-risk patient group. 


\section{Current evidence on TAVR}

The most experience with TAVR exists with two valve systems: the SAPIEN valve system along with its successor SAPIEN XT (both Edwards Lifescience, Irvine, CA, USA) and the CoreValve ${ }^{\circledR}$ System (Medtronic, Minneapolis, MN, USA). ${ }^{7}$ The SAPIEN valve is a balloon-expandable valve that can be introduced both transapically and transarterially, at which a fully percutaneous insertion is possible. The CoreValve is a self-expanding valve that is only available for a transarterial approach, which can be performed fully percutaneously as well. ${ }^{7}$

Most published studies on TAVR results are based on national registries or on post-marketing surveillance registries. The major drawback of this data is that patient inclusion in registries is often voluntary and that data is self-reported. Further, inclusion criteria and endpoint definitions vary, thus rendering comparisons is difficult. However, registries allow the inclusion of large patient samples and observation of patient outcomes in a real-world setting. ${ }^{7,8}$ Major registries and important outcome data are summarized in Table 1. The French Aortic National CoreValve and Edwards (FRANCE) 2 registry is currently the largest published registry and includes 3195 patients. It comprises all patients who had a TAVR in France between January 2010 and October 2011. ${ }^{9}$ Similar to the French registry, the UK Transcatheter Aortic Valve Implantation registry (UK TAVI) is a mandatory registry including all consecutive patients undergoing TAVR within the UK. A further advantage of this registry is that mortality follow-up has been confirmed by cross-checking the data with an independent national institution. ${ }^{10}$ Though the registry data are hard to compare due to varying inclusion criteria, procedural data, and endpoint definitions, some general observations can be made. Essential outcome data are similar in the major TAVR registries: mean age is slightly above 80 years, with an average logistic European System for Cardiac Operative Risk Evaluation (EuroSCORE) ${ }^{11}$ of between 18.5 and 29.1. Procedural success is between $91.7 \%$ and $98.7 \%$, and is probably dependent on definition and learning curve. Some $7.1 \%-12.4 \%$ of patients die within 30 days of their TAVR, while 1-year mortality is $18.9 \%-27.9 \% .^{9}, 10,12-14$

The CoreValve Italian registry is one of the few registries that published follow-up data for up to 3 years. According to this registry, 3 -year survival was $65.2 \%$ of patients implanted between June 2007 and August 2008. Echocardiographic follow-up showed no signs of increasing valve deterioration at 3 -years of follow-up. ${ }^{12}$ Although the mortality rates reported are high, they are explicable due to old age and associated comorbidities of the patient population: the yearly mortality of an octogenarian in Europe is 9.1\%. ${ }^{15,16}$ Most registries report that causes of death during follow-up are mainly noncardiovascular. ${ }^{12,15}$

Registry data ${ }^{9,10,12-14}$ on procedural complications vary, which could be explained due to different definitions of adverse events; for instance, "stroke" might include

Table I Major registry data

\begin{tabular}{|c|c|c|c|c|c|c|c|}
\hline & $\begin{array}{l}\text { UK TAVI } \\
\text { registry }\end{array}$ & $\begin{array}{l}\text { German TAVI } \\
\text { registry }\end{array}$ & $\begin{array}{l}\text { FRANCE } 2 \\
\text { registry }\end{array}$ & $\begin{array}{l}\text { CoreValve } \\
\text { Italian registry }\end{array}$ & I-TA & $\begin{array}{l}\text { SOURCE } \\
\text { registry }\end{array}$ & $\begin{array}{l}\text { SOURCE } \\
\text { registry }\end{array}$ \\
\hline & Moat et al ${ }^{10}$ & Zahn et $\mathrm{al}^{13}$ & Gilard et al ${ }^{9}$ & Ussia et $\mathrm{al}^{12}$ & $\begin{array}{l}\text { D'Onofrio } \\
\text { et al }{ }^{126}\end{array}$ & Thomas et $\mathrm{al}^{14}$ & \\
\hline \multirow[t]{2}{*}{ Valve type } & SAPIEN valve & CoreValve & CoreValve & CoreValve & SAPIEN valve & SAPIEN valve & \\
\hline & & SAPIEN valve & SAPIEN valve & & & & \\
\hline Approach, \% & $\begin{array}{l}\text { Transfemoral, } \\
69.0\end{array}$ & $\begin{array}{l}\text { Transfemoral, } \\
92.4\end{array}$ & $\begin{array}{l}\text { Transfemoral, } \\
74.6\end{array}$ & $\begin{array}{l}\text { Transfemoral, } \\
95.0\end{array}$ & $\begin{array}{l}\text { Transapical, } \\
100\end{array}$ & $\begin{array}{l}\text { Transfemoral, } \\
44.6\end{array}$ & $\begin{array}{l}\text { Transapical, } \\
55.4\end{array}$ \\
\hline Patients, N & 870 & 697 & 3195 & 181 & 504 & 463 & 575 \\
\hline Log EuroSCORE, \% & 18.5 & $20.5 \pm 13.2$ & $21.9 \pm 14.3$ & $24.0 \pm 13.5$ & 26.3 & 25.8 & 29.1 \\
\hline Mean age, years & $81.9 \pm 7.1$ & $81.4 \pm 6.3$ & $82.7 \pm 7.2$ & $80.9 \pm 6.1$ & & $81.7 \%$ & $80.7 \%$ \\
\hline Procedural success, \% & 97.3 & 98.7 & 96.9 & 91.7 & 99.0 & & \\
\hline \multicolumn{8}{|l|}{ 30-day results, \% } \\
\hline Mortality & 7.1 & 12.4 & 9.7 & 11.2 & 8.3 & & \\
\hline Stroke & 4.1 & 2.8 & 3.4 & 2.8 & 3.0 & & \\
\hline $\begin{array}{l}\text { Major vascular } \\
\text { complication }\end{array}$ & 6.3 & & 4.7 & 3.3 & & & \\
\hline $\begin{array}{l}\text { Moderate/Severe } \\
\text { regurgitation }\end{array}$ & 13.6 & 17.5 & 18.5 & 15.2 & & & \\
\hline Pacemaker & 16.3 & 39.3 & 15.6 & 12.1 & 5.4 & & \\
\hline I-year mortality, \% & 21.4 & 20.2 & 24.0 & 23.6 & 18.8 & 18.9 & 27.9 \\
\hline
\end{tabular}

Abbreviations: EuroSCORE, European System for Cardiac Operative Risk Evaluation; FRANCE, French Aortic National CoreValve and Edwards; I-TA, Italian Registry of Trans-Apical Aortic Valve Implantation; SOURCE, SAPIEN Aortic Bioprosthesis European Outcome; TAVI, transcatheter aortic valve implantation.

Note: SAPIEN valve (Edwards Lifescience, Irvine, CA, USA); CoreValve (Medtronic, Minneapolis, MN, USA). 
only patients with permanent neurologic damage or both permanent and transient events. Stroke occurred in $2.8 \%-4.1 \%$, myocardial infarction in $0.3 \%-5.1 \%$, and major vascular complications in 3.3\%-6.3\% of all cases. Bleeding complications are the most frequently associated adverse event $(10.7 \%-12.1 \%)$. Further, $13.6 \%-18.5 \%$ of patients were reported to have at least moderate aortic or paravalvular regurgitation on follow-up., ${ }^{9,12-14}$

Registries provide valuable information on patient outcome in daily clinical practice. However, randomized controlled trials are indispensable for obtaining evidence regarding the question of who will benefit from TAVR. The PARTNER (Placement of Aortic Transcatheter Valves) Trial ${ }^{17}$ is the first randomized controlled multicenter trial on TAVR for symptomatic severe aortic stenosis that has been completed. A total of 1057 patients were enrolled in two trial arms: PARTNER A randomized "high-risk" patients to SAVR or TAVR via a transfemoral or transapical approach using the Edwards SAPIEN Valve. PARTNER B randomized patients deemed "inoperable" to transfemoral TAVR or standard therapy. ${ }^{17}$ The trial was sponsored by Edwards Lifescience and conducted under US Food and Drug Administration (FDA) surveillance at 25 centers in the USA, Canada, and Germany. Patients that were ineligible for TAVR due to anatomical criteria and patients presenting with very high-risk comorbidities such as reduced ejection fraction, recent stroke, or severe renal insufficiency were excluded from the trial. Obviously, treatment allocation could not be blinded. Most trial centers did not have prior experience with TAVR, but were trained in a program before the trial. The primary endpoint was all-cause mortality; secondary endpoints included a composite endpoint of major cardiovascular and cerebrovascular events, length of hospital stay, functional status, and quality-of-life assessment. ${ }^{18}$

High-risk patients $(\mathrm{n}=699)$ in PARTNER A were required to have a Society of Thoracic Surgeons (STS) score of at least $10 \%$ and a surgeons' assessment of risk of death by 30 days of above $15 \%$. Patients were divided into a group with possible transfemoral access and transapical access before being randomized to either SAVR or TAVR. PARTNER A was designed to assess non-inferiority of TAVR versus SAVR for all TAVR and femoral TAVR alone. ${ }^{17}$ Baseline characteristics were similar between patients who had SAVR and TAVR. However, the group of patients receiving transapical TAVR had more previous coronary artery bypass grafting or coronary interventions, peripheral or carotid artery disease, cerebrovascular disease, and porcelain aortas. ${ }^{17}$ For TAVR, procedural success was $90.5 \%$. Mortality at
30 days post-procedure revealed no significant difference between TAVR (3.4\%) and SAVR $(6.5 \%, P=0.07)$, with similar results for the subgroups receiving transfemoral and transapical TAVR. Likewise, there was no significant difference in 1-year mortality between TAVR and SAVR, which had a mortality of $24.2 \%$ and $26.8 \%$, respectively, thus meeting non-inferiority for TAVR versus SAVR in this patient population. ${ }^{17}$ At 2 years post-procedure, mortality was $33 \%$ in the TAVR group and $35.0 \%$ in the SAVR group, still showing no significant difference. ${ }^{19}$ Neurologic events were more frequent with TAVR at follow-up at 30-days as well as at 2-years. ${ }^{20}$ Bleeding complications were less frequent with TAVR than in the surgery group, whereas vascular complications and paravalvular regurgitation occurred more often after TAVR.${ }^{17}$ During follow-up, regurgitation remained unchanged or improved in the majority of patients. However, the presence of aortic or paravalvular regurgitation to any degree was associated with increased late mortality. ${ }^{19}$ Both SAVR and TAVR resulted in hemodynamic improvements, reduced mean gradients, and increased aortic valve areas that remained stable during 2 years of follow-up. ${ }^{19}$

PARTNER B $(\mathrm{n}=358)$ included patients who were judged by two surgeons to be inoperable based on a risk of death and irreversible morbidity above $50 \%$. Patients were randomized to either transfemoral TAVR or standard therapy, which included balloon valvuloplasty in $83.7 \%$ of patients. Baseline characteristics in both treatment arms were similar. This study arm was designed to assess the superiority of TAVR versus standard treatment. ${ }^{17,21}$ After 30 days, mortality of patients undergoing TAVR was $5.0 \%$ versus $2.8 \%$ with standard therapy $(P=0.06)$. At follow-up at 1 year and at 2 years, mortality was significantly lower in patients who underwent TAVR rather than standard therapy $(30.7 \%$ versus [vs] $50.7 \%$ at 1 year, respectively, $43.3 \%$ vs $68.0 \%$ at 2 years, respectively). TAVR was also superior to medical treatment in terms of repeat re-hospitalization and functional status as assessed by the New York Heart Association (NYHA) classification. ${ }^{21}$ Interestingly, there was a significant association between STS score and mortality after TAVR. In patients with high STS scores, the survival benefit of TAVR was reduced: Makkar et $\mathrm{al}^{21}$ reported that in patients with an STS score above $15 \%$, the survival benefit was no longer significant. They concluded that in patients with exceedingly severe comorbidities, TAVR might be futile. ${ }^{21}$ Further, similar to in PARTNER A, neurologic events occurred more frequently after TAVR. ${ }^{17,21}$ Hemodynamic performance of the valve remained stable during 2 years of follow-up. Moderate to severe central or paravalvular regurgitation was detected 
in $14.7 \%$ of patients at 1 year and improved or did not change during follow-up in most cases. ${ }^{17,21}$ Considering both paravalvular and central aortic regurgitation, the degree of total aortic regurgitation was similar in patients with TAVR versus standard therapy. ${ }^{21}$ Consistent with the results of PARTNER A, moderate or severe paravalvular regurgitation was associated with a trend toward higher mortality. ${ }^{21}$

When interpreting the results of the PARTNER Trial, several confounders and sources of bias have to be taken into consideration. Due to the nature of procedures compared, the trial had to be open label. Further, inclusion was partly based on the treating teams' judgment and the assignment "high-risk" versus "inoperable" was not based on objective criteria. There were also some differences in the baseline characteristics of the treatment arms, and considerable imbalance in the percentage of patients who died or withdrew before the procedure. In the SAVR group, patients with concomitant procedures such as coronary artery bypass graft and mitral valve repair were included, even though the risk of a combination procedure is known to be higher than with isolated SAVR. Besides this, there was a standardized antithrombotic regimen after TAVR, but no standard therapy after SAVR. Finally, as previously mentioned, Edwards Lifescience sponsored the trial, and the majority of treatment centers had potential financial conflicts of interest. ${ }^{22}$

Compared to other non-randomized trials on TAVR, the results of PARTNER both for SAVR and TAVR showed lower mortality and reduced rates of adverse events. This is probably due to the exclusion of several high-risk patient subgroups (eg, recent stroke, severe left-ventricular dysfunction, kidney failure). Thus, the results of PARTNER cannot be generalized to the patient population presenting for AVR in daily clinical practice. Nevertheless, PARTNER is a landmark trial in that it constitutes the first randomized controlled trial comparing TAVR with SAVR and medical therapy, respectively. Summarized, PARTNER A showed that results of a TAVR are comparable to the results of an SAVR in high-risk patients with regard to mortality at 2 years' follow-up. The risk of neurologic events seems to be higher with TAVR, especially within the first weeks after the procedure. Paravalvular regurgitation is more common after TAVR and is associated with increased mortality. PARTNER $B$ indicated a mortality reduction with TAVR versus standard therapy in patients judged inoperable. Further, TAVR increased functional status and reduced frequency of re-hospitalizations. Similar to the results of PARTNER A, the risk of neurologic events was higher with TAVR. However, even though the survival benefit of a TAVR was significant in PARTNER, one-third of the patients who had a TAVR died within 1 year. This is probably because there is a group of patients with very severe comorbidities for whom a TAVR is no longer beneficial. ${ }^{17,21}$

Another randomized controlled trial comparing TAVR with SAVR was the STACCATO (Surgical Aortic Valve Replacement in Operable Elderly Patients with Aortic Stenosis) trial, which aimed for the expansion of the indication for TAVR to intermediate-risk patients. All TAVRs were performed via the transapical route. However, the trial had to be terminated after the inclusion of 70 patients because of an excess of adverse events in the TAVR group. This result could have been due to a statistical coincidence or insufficient preoperative imaging; nevertheless, the results of this study should be taken into account before prematurely suggesting TAVR to lower-risk patients. ${ }^{8,23}$

Long-term follow-up and further randomized controlled trials are needed to provide further evidence on the role of TAVR in the treatment of aortic stenosis. PARTNER II will compare the performance of the new Edwards Lifescience SAPIEN XT with its predecessor, the SAPIEN valve. In analogy to the PARTNER Trial, the CoreValve US Pivotal Trial is currently randomizing patients to TAVR with Medtronic CoreValve or SAVR. Further, to assess the role of TAVR in lower-risk groups, the SURTAVI (Safety and Efficacy Study of the Medtronic CoreValve ${ }^{\circledR}$ System in the Treatment of Severe, Symptomatic Aortic Stenosis in Intermediate Risk Subjects who Need Aortic Valve Replacement) trial will randomize intermediate-risk patients to TAVR with CoreValve and SAVR. ${ }^{24,25}$

\section{Patient selection for TAVR}

In 2012, TAVR was integrated into the European Society of Cardiology (ESC)/European Association for CardioThoracic Surgery (EACTS) guidelines on the management of valvular heart disease. ${ }^{3}$ The guidelines recommend TAVR in patients with severe symptomatic aortic stenosis who are considered unsuitable for surgery, as well as in high-risk patients who might still be surgical candidates. ${ }^{3}$ TAVR is not recommended in patients with a life expectancy of less than 1 year, or an unlikely improvement in quality of life as a result of undergoing a TAVR. ${ }^{3}$ These recommendations are primarily based on the results of the PARTNER Trial. As already mentioned, Makkar et $\mathrm{al}^{21}$ reported that, in PARTNER B, a subgroup of patients with an STS score over $15 \%$ did not benefit from TAVR. Further, TAVR is not recommended if the patient has associated disease of other valves that makes a major contribution to symptoms and which is only treatable by surgery. ${ }^{3}$ 
However, the selection of an adequate target population for TAVR remains difficult. Both logistic EuroSCORE and STS score ${ }^{26}$ have been proposed to identify patients who might benefit from TAVR, with a suggested cut-off point at a logistic EuroSCORE of $20 \%$ or an STS score of over $10 \%$. However, the logistic EuroSCORE is known to highly overestimate mortality in isolated SAVR as well as in TAVR. STS score and EuroSCORE II seem to be more accurate predictors of mortality but are still insufficient to adequately identify patients for TAVR. ${ }^{27-33}$

A particular disadvantage of all these scoring systems is that conditions such as porcelain aorta, liver cirrhosis, pulmonary hypertension, severe chronic obstructive pulmonary disease, patent coronary bypass grafts, chest radiation, and frailty are not fully taken into consideration., ${ }^{3,17,33}$ While a specific scoring system for TAVR is awaited, an individualized clinical decision by the treating team of cardiologists and cardiac surgeons is recommended. 3,27,29,30,33

A number of independent risk factors associated with poor outcome after TAVR has been identified. In the PARTNER Trial, low body mass index, prior stroke, low mean gradient, creatinine level at baseline, prior vascular surgery or stent, and chronic obstructive pulmonary disease requiring oxygen were shown to be predictors of mortality. ${ }^{17,19,21}$ Additional risk factors are left-ventricular dysfunction, coronary artery disease, diabetes, prior balloon valvuloplasty, prior acute pulmonary edema, and tricuspid regurgitation, whereas the impact of mitral regurgitation is still unclear. ${ }^{10,34-36}$

Apart from clinical factors, there are a number of anatomical contraindications for TAVR that have been summarized in the ESC/EACTS guidelines that will be discussed in detail further on in this article. They include an annulus size smaller than $18 \mathrm{~mm}$ or larger than $29 \mathrm{~mm}$, endocarditis or left-ventricular thrombus, high risk of coronary ostium obstruction, plaques with thrombi in the aortic arch, and inadequate vascular or transapical access. ${ }^{3}$ Bicuspid or noncalcified valves, hemodynamic instability, a LVEF below $20 \%$, and untreated coronary artery disease are considered relative contraindications by the ESC/EACTS consensus guidelines. ${ }^{3}$

The encouraging results of the first trials of TAVR have resulted in a trend toward the selection of lower-risk patients for TAVR. The FRANCE 2 registry reported significant reduction of the EuroSCORE of patients included between 2010 and 2011, and the proportion of patients declining SAVR in favor of TAVR has markedly increased. ${ }^{9}$

Even though non-inferiority has been shown for TAVR in high-risk patients, ${ }^{19}$ and although small case series have reported favorable valve durability of up to 5 years, ${ }^{37}$ we still know little about the long-term outcome of a TAVR. Along with a number of issues such as stroke rate and paravalvular leakage associated with TAVR, these facts should be kept in mind before suggesting TAVR to low-risk patients who might be candidates for SAVR.

\section{Imaging assessment}

Preoperative imaging assessment is crucial to assess access routes, aortic root anatomy, prosthesis size, and optimal fluoroscopic projection planes. ${ }^{38,39}$

As vascular injury is one of the most frequent complications of TAVR, occurring in approximately $10 \%$ of patients, ${ }^{40} \mathrm{a}$ thorough imaging of the arterial vasculature is essential before choosing the most suitable access route. ${ }^{30} \mathrm{~A}$ basic assessment can be done by conventional angiography - for example, at the time of coronary angiography. However, more detailed information on luminal diameter, atherosclerosis, and vessel tortuosity can be gained by multidetector computed tomography (MDCT). ${ }^{39,41}$ MDCT allows measuring luminal diameter at an exactly orthogonal plane to the vessel by using multiplanar reconstructions. ${ }^{38}$

The high risk of vascular injury in TAVR via a peripheral access is due to the large introducer sheaths, though a substantial reduction in sheath diameter has been achieved over the last few years. The CoreValve Revalving System is inserted via an 18 French sheath, while the SAPIEN XT Valve Delivery System ranges from 16 to 20 French, depending on the size of the valve. Expectedly, the higher the atherosclerotic burden and the degree of tortuosity, the higher the risk of vascular injury. ${ }^{38}$ Hayashida et $\mathrm{al}^{42}$ reported that the ratio of sheath diameter to luminal diameter of the artery should be lower than 1.05 to minimize the risk of arterial damage. In heavily calcified arteries, the maximum ratio should be 1.00, whereas noncalcified, flexible vessels allow a ratio of 1.10. Additional predictors of vascular complications are concentric calcifications and calcifications surrounding more than $180^{\circ}$ of the vessel circumference..$^{38,39,41,42}$

Similarly, the lower the atherosclerotic burden, the higher the accepted vessel tortuosity. A flexible vessel will stretch during advancement of the sheath, even with kinking angles over $90^{\circ} .3^{38,43}$ Further useful findings on MDCT can be calcifications of the aortic arch, aortic thrombi, dissections, stents, and coronary or vascular bypass grafts. If a transapical access is planned, the orientation of the left-ventricular apex and outflow tract as well as the presence of left-ventricular thrombi can be shown on MDCT. ${ }^{38}$

The most important preoperative investigation to determine feasibility of TAVR and to ensure procedural 
success is assessment of the aortic root. In most centers, multimodality imaging using echocardiography, angiography, and electrocardiography-gated MDCT is used to evaluate the anatomy of the aortic root. The essential information that needs to be obtained is the diameter and calcification of the aortic annulus; the projection plane of the aortic annulus; the cuspidity, length, and calcification of the aortic leaflets; location of the coronary ostia; and the dimensions and extent of calcification of sinuses of Valsalva, sinutubular junction, and ascending aorta. ${ }^{38,39}$

The size of the annulus is necessary to determine the optimal size of the prosthesis, which is usually chosen slightly larger than the measured annular diameter to ensure stable positioning of the valve. ${ }^{7,33}$ The SAPIEN valve comes in diameters of 23, 26 , and $29 \mathrm{~mm}$ and is recommended for annular diameters of 18-27 mm, while the CoreValve Revalving System is somewhat larger and comes in diameters of 26, 29, and $31 \mathrm{~mm}$ for annular diameters of 20-29 $\mathrm{mm}$. If the prosthesis chosen is too small, the valve can dislodge from its designated position, and paravalvular regurgitation is more likely. If the valve is too large, annular rupture can occur, or incomplete expansion of the valve might cause aortic regurgitation. ${ }^{7,38}$

The "annulus" is defined as the ring built by the lowest hinge points of the three valvular leaflets. It can be measured by transthoracic or transesophageal echocardiography (TEE), angiography, or MDCT, which often result in different measurements due to the elliptical shape of the annulus. Additionally, the exact plane of the annulus has to be determined to prevent transverse measurement. Echocardiography usually underestimates the annular diameter in comparison to MDCT. Ideally, measurements should be taken in systole. Since there is no evidence yet which imaging modality should be preferred, most surgeons or interventionists use both MDCT and echocardiography to obtain an optimal appreciation of the aortic root anatomy. ${ }^{38,39}$

To minimize the risk of coronary artery obstruction by dislodging debris during balloon or valve expansion, the distance of the coronary ostia to the annulus should be assessed preoperatively. Though no definite minimum distance has been established, a minimal distance of 10-14 $\mathrm{mm}$ has been suggested for the SAPIEN valve. Short and shallow sinuses of Valsalva as well as heavily calcified and elongated cusps probably further increase the risk of coronary obstruction. For CoreValve implantation, the manufacturer suggests a minimum height of the sinuses of Valsalva of $15 \mathrm{~mm}$, a diameter of the sinuses of more than 27-29 $\mathrm{mm}$, and an ascending aortic diameter of less than $40-43 \mathrm{~mm}$ depending on the size of the valve. ${ }^{38,44}$
John et al have shown that the overall calcific burden of the aortic root correlates with post-procedural paravalvular regurgitation ${ }^{45}$ and this has also been suggested to influence the risk of valve dislodgement, annular rupture, and embolic stroke. ${ }^{38,44}$

Finally, MDCT can be used to detect the optimal projection plane for the procedure to show the aortic annulus in an orthogonal view, usually with the right cusp in a central position and the left and non-coronary cusps to the sides. ${ }^{38}$

\section{Access routes}

TAVR is possible retrogradely via a transfemoral, transaxillary, direct aortic, or even transcarotid approach, or via an anterograde approach through the left-ventricular apex. In most centers, the femoral arteries are the preferred access route. Only if a femoral approach is not feasible are other alternative access routes considered. ${ }^{46}$

Femoral access is very attractive, as it allows a fully percutaneous procedure; although in some cases, a femoral cut down may be required. Smaller introducer sheaths and percutaneous vascular closure devices have significantly facilitated the percutaneous approach over the past few years, and several new closure devices are currently under clinical evaluation. ${ }^{47}$ However, one of the most important disadvantages of the transfemoral access route is the risk of vascular injury, especially if a large valve is needed or if the patient's vasculature is unfavorable. Therefore, preoperative imaging is crucial to determine the feasibility of a transfemoral approach. Further, a transfemoral transcatheter valve is more difficult to position than a valve inserted via a more direct approach..$^{38,39,41,42,46,48}$ Some studies have reported a higher incidence of neurologic events with the transfemoral route, which is probably because the sheath has to pass through the curved aortic arch, but others could not support these findings..$^{40,49,50}$

Introducing the valve through the left-ventricular apex is performed via a left anterior thoracotomy through the fifth or sixth intercostal space. After opening the pericardium, purse string sutures are placed around the apex and the sheath of the valve is inserted. Rapid pacing is needed for valve positioning and for closure of the apex, and it has to be kept in mind that cardiac output might be compromised during sheath introduction. ${ }^{25}$

Of the two most commonly used valves, only the SAPIEN can be inserted transapically. ${ }^{48,51}$ The transapical approach is feasible in the majority of patients, with exception of a few in whom a left-ventricular aneurysm or adhesions might prohibit this access route. ${ }^{46,48}$ Avoiding a peripheral access 
is a major advantage for the large group of patients with peripheral vascular disease. Additionally, the insertion point is close and in a straight line to the aortic valve, rendering valve positioning easier and more precise ${ }^{46}$ The possibility of a reduced stroke rate is under discussion. ${ }^{40,44}$

Since a thoracotomy is required, the transapical approach constitutes an invasive surgical procedure, resulting in increased postoperative pain and a higher risk of respiratory complications. ${ }^{46}$ Therefore, the transapical access route might be less ideal for patients with severe pulmonary comorbidities. ${ }^{48}$ Bleeding and tamponade, myocardial injury, ventricular aneurysm formation, and damage to the mitral valve are rare but possible risks that must be considered. Barbash et $a l^{52}$ assessed the degree of apical ventricular dysfunction after transapical TAVR and concluded that $30 \%$ of patients showed apical dysfunction that was associated with a nonsignificant trend toward a reduced ejection fraction. The dysfunction was transient in $50 \%$ of cases and did not affect mortality. ${ }^{52}$

To ease the procedure, a number of apical access and closure devices have been developed, some of which are currently undergoing clinical evaluation. ${ }^{47}$

Most studies comparing the transfemoral and transapical approach did not show a significant difference regarding mortality. ${ }^{48,49,53,54}$ When reviewing data on the comparison of these two access routes, it must be noted that most centers have a "femoral-first" approach. Subsequently, the patient subgroups undergoing transfemoral and transapical TAVR usually show significant differences with regard to their baseline characteristics. As an example, in PARTNER A, patients having transapical TAVR had significantly more coronary artery disease, cerebrovascular disease, peripheral artery disease, and porcelain aortas. ${ }^{17}$

Bleiziffer et ${ }^{4}{ }^{49}$ reported their experience with 203 patients undergoing TAVR and did not show a significant influence of the choice of access route on survival. The procedure was faster using the femoral access route, but longer fluoroscopy and larger volume of contrast agent were required. There was no significant difference concerning intra-procedural hemodynamic status, postoperative renal insufficiency, or improvement of functional status. Although the type of access site complications were different (eg, vessel rupture or hematoma for femoral access, bleeding or tamponade for transapical access), they occurred with a similar frequency, and were fatal in a similar percentage of patients. A significant difference was shown concerning the incidence of periprocedural stroke, which occurred in 5\% of transfemoral cases and none of the transapical patients.
Eggebrecht et al reported similar findings. ${ }^{50}$ In contrast, a recent meta-analysis did not confirm a reduced incidence of neurologic events with the transapical access. ${ }^{40}$ Thus, a benefit of the transapical approach concerning the stroke rate remains unclear.

While most studies suggest that the choice of access route itself does not have a significant impact on mortality, ${ }^{42,48,49,53}$ both procedures have specific advantages and risks. More precise decisive algorithms need to be defined to individually choose the ideal access route for each patient.

Although the transfemoral and transapical are the most commonly used approaches, a number of alternative access routes have been proposed over the last few years. ${ }^{46}$ The direct aortic approach can be performed via an upper partial hemisternotomy or a right anterior mini-thoracotomy. An anterior thoracotomy is advantageous if patent coronary artery bypass grafts have to be avoided, whereas a sternotomy avoids opening the pleural space..$^{51}$ The direct approach has been successfully employed and described by several groups using both the CoreValve and the SAPIEN valve. ${ }^{55-57}$ Depending on the type of valve, a specific distance between the aortic valve and the insertion point in the ascending aorta is required. ${ }^{51}$ Since cardiac surgeons are used to handling the ascending aorta for cannulation and access, they usually feel very comfortable with this approach. Compared with the transfemoral access route, valve positioning is easier due to the shorter distance, and myocardial injury is avoided ${ }^{46}$ Nevertheless, the transaortic access route requires an invasive surgical procedure.

Bapat et $\mathrm{al}^{55}$ showed that even a porcelain aorta is not necessarily a contraindication to transaortic TAVR as long as a small calcification-free segment can be identified. ${ }^{55,56}$ An increased risk of stroke has been discussed but has not been confirmed yet. ${ }^{56}$ If the ascending aorta is not accessible, the brachiocephalic artery has been proposed as a possible alternative. ${ }^{58}$

Another alternative access route is the subclavian or axillary artery. It is usually accessed by surgical cut down, although the feasibility of a percutaneous access route has been shown. ${ }^{6}$ In comparison to the femoral access approach, the device is easier to position with the subclavian approach due to the proximity of the access site to the aortic valve. Using the right subclavian artery has been reported to be difficult if the aortic annulus is more than $30^{\circ}$ off to the horizontal plane, and preoperative imaging should be used to assess tortuosity and calcifications of the vessel. ${ }^{51,59} \mathrm{~A}$ further limitation is the presence of a patent internal mammarian bypass graft, which might be occluded or dissect during the procedure. ${ }^{51,59}$ Several case series have been published on this access route. ${ }^{59}$ For 
example, Petronio et al published a case series comparing the subclavian and femoral access routes and reported similar outcomes with regard to mortality and morbidity, with no specific complications related to the former route. ${ }^{60}$

Other alternative access routes that have been described include a carotid access ${ }^{61}$ as well as a surgical cut down to the common iliac arteries. ${ }^{62}$

Since randomized controlled trials comparing access routes are still awaited, larger clinical trials are necessary to specify the role of the different approaches for TAVR.

\section{Types of transcatheter heart valves}

The SAPIEN valve and its successor, the SAPIEN XT, are bovine pericardial valves with a cobalt chromium frame that are balloon expandable and can be used both for anterograde and retrograde access routes. Apart from the aortic position, they can be used for pulmonary valve replacement and for valve-in-valve procedures for all four heart valves. ${ }^{6,7,38}$

The CoreValve Revalving System consists of porcine pericardial leaflets in a self-expandable nitinol frame. It can only be introduced retrogradely. Its larger frame expands into the left-ventricular outflow tract and the ascending aorta to ensure stable positioning of the valve. Rapid pacing is not necessary for the deployment of the CoreValve System, and the valve can, with limitation, be repositioned after partial deployment. Its annular diameters are somewhat larger than those of the SAPIEN valve, while its introducer sheath is smaller than the sheath of the SAPIEN XT, depending on the size of the valve. , $^{6,38}$

As yet, there are no randomized controlled trials comparing the outcome of TAVR using the SAPIEN valve and CoreValve, but, at the time of writing, data from registries and retrospective matched comparisons do not indicate that valve design has a significant impact on survival and most major postoperative complications..$^{9,10,63}$ There is clear evidence that the risk of heart block that requires a permanent pacemaker is higher after CoreValve implantation, which might be due to the extended frame expanding into the left-ventricular outflow tract. ${ }^{1,10,63-66}$ Several studies have further suggested that paravalvular and central regurgitation might be more common after CoreValve implantation, ${ }^{9,10,63}$ while others have been unable to demonstrate significant differences. ${ }^{64}$

Some studies support that the SAPIEN valve might be associated with higher gradients and lower orifice areas, and that this valve might carry a higher risk of coronary artery obstruction. ${ }^{6,63}$ However, as randomized controlled trials comparing devices for TAVR are pending, no evidence-based recommendation for one of the devices can be given.
Several new transcatheter heart valves have been developed over the last few years (Table 2). Some have recently obtained CE-mark approval, while others are still in early clinical evaluation. ${ }^{6,47}$ Most of them are repositionable and retrievable. Further features include anatomical alignment and increased annular sealing to reduce paravalvular regurgitation. Some can be deployed without rapid pacing. ${ }^{47,67-74}$

Clinical data on second-generation transcatheter heart valves are still limited. Long-term data and comparative studies are awaited to determine which new development will have a relevant positive impact on clinical outcome.

\section{Periprocedural management and procedural performance}

The 2012 American College of Cardiology Foundation/ American Association for Thoracic Surgery/Society for Cardiac Angiography and Interventions/STS expert consensus document on TAVR provides general recommendations on the performance of TAVR. ${ }^{7}$ In most centers, the TAVR procedure is performed by a team that includes an interventional cardiologist, a cardiothoracic surgeon, and their teams. Further important members of the team are a cardiac anesthesiologist and a perfusionist in case cardiopulmonary bypass (CPB) is necessary. Ideally, the procedure should take place in a hybrid operating room. The location should provide adequate fluoroscopic imaging and full interventional cardiology equipment as well as surgical equipment including that for $\mathrm{CPB} .^{7}$

Typically, the procedure is performed under general anesthesia, even though local anesthesia with conscious sedation for transfemoral TAVR has been described. ${ }^{75}$ Anesthetic management should include TEE. A transvenous pacemaker or an epimyocardial pacing wire should be placed for rapid ventricular pacing if required or to permit ventricular pacing in case of post-procedural heart block. During the procedure, heparin should be administered to maintain an activated clotting time of 250-300 seconds, which can be reversed by protamine at the end of the procedure. Attention should be paid to volume depletion in those elderly patients with typically severely hypertrophied ventricles. Both prolonged hypotension - for example, due to repeated episodes of rapid ventricular pacing - and tachycardia should be avoided. If rapid ventricular pacing is required during valve deployment, it is advisable to test the patient's response to rapid pacing before the procedure, especially in patients with reduced ventricular ejection fraction. ${ }^{7,44,48}$

At the beginning of the procedure, guide wires for possible CPB cannulation are inserted in the femoral 
Table 2 Emerging transcatheter heart valves

\begin{tabular}{|c|c|c|c|c|c|c|c|}
\hline Valve & Transapical & Transfemoral & Repositionable & $\begin{array}{l}\text { Anatomical } \\
\text { alignment }\end{array}$ & $\begin{array}{l}\text { Increased } \\
\text { annular } \\
\text { sealing }\end{array}$ & $\begin{array}{l}\text { No rapid } \\
\text { pacing }\end{array}$ & Other \\
\hline $\begin{array}{l}\text { JenaValve }{ }^{47} \\
\text { (JenaValve Technology, Munich, Germany) }\end{array}$ & $x$ & $x$ & $x$ & $x$ & $x$ & $x$ & \\
\hline $\begin{array}{l}\text { Acurate }^{T M} \text { Aortic Valve } \\
\text { (Symetis, Ecublens, Switzerland) }\end{array}$ & $x$ & $x$ & $x$ & $x$ & $x$ & & \\
\hline $\begin{array}{l}\text { Engager }^{\mathrm{TM}} \text { Aortic Valve Bioprosthesis }{ }^{72} \\
\text { (Medtronic, Minneapolis, MN, USA) }\end{array}$ & & $x$ & $x$ & $x$ & $x$ & & \\
\hline $\begin{array}{l}\text { Portico }{ }^{\mathrm{TM}} \text { Transcatheter Heart Valve } \\
\text { (St Jude Medical, Little Canada, MN, USA) }\end{array}$ & & $x$ & $x$ & & & $x$ & \\
\hline $\begin{array}{l}\text { Direct Flow Medical }{ }^{\circledR} \text { Transcatheter } \\
\text { Aortic Valve System }{ }^{70} \\
\text { (Direct Flow Medical, Santa Rosa, CA, USA) }\end{array}$ & & $x$ & $x$ & & $x$ & & Nonmetallic \\
\hline $\begin{array}{l}\text { Sadra Lotus }{ }^{T M} \text { Valve System } \\
\text { (Boston Scientific, Natick, MA, USA) }\end{array}$ & & $x$ & $x$ & & $x$ & & \\
\hline $\begin{array}{l}\text { CENTERA Transcatheter Heart } \\
\text { Valve System }{ }^{73} \\
\text { (Edwards Lifescience, Irvine, CA, USA) }\end{array}$ & & $x$ & $x$ & & $x$ & & $\begin{array}{l}\text { Motorized } \\
\text { 14 Fr sheath }\end{array}$ \\
\hline $\begin{array}{l}\text { SAPIEN } 3 \text { valve }{ }^{73} \\
\text { (Edwards Lifescience) }\end{array}$ & & $x$ & & & $x$ & & I4 Fr sheath \\
\hline
\end{tabular}

Abbreviation: Fr, French.

vessels if necessary. A pigtail catheter is positioned in the aortic root for aortography. Depending on the approach, the access site is then punctured or surgically exposed and the sheaths inserted. The aortic valve is crossed with a guide wire and usually balloon valvuloplasty is performed during rapid pacing before valve deployment. Subsequently, the transcatheter heart valve is positioned in the aortic annulus guided by fluoroscopy and TEE then deployed. Depending on the type of valve, rapid ventricular pacing might be necessary during valve deployment. After an episode of rapid pacing, the patient should be given time for hemodynamic recovery. Following the deployment of the valve, valve position, function, regurgitation, and the patency of the coronary ostia should be assessed by angiography and TEE. Angiography should be used to exclude damage to the access vessel if a peripheral access was used. If the result of the procedure is satisfactory, the catheters and sheaths are removed and the access site closed., ${ }^{74,76,77}$ After an uneventful procedure, extubation can be considered if the patient's respiratory and hemodynamic status is stable. All patients should be transferred to the intensive care unit for post-procedural observation. ${ }^{7,48}$ Since atrioventricular (AV) conduction disturbances are a known complication of TAVR, post-procedural monitoring for $24-48$ hours is advisable. Telemetry should be prolonged if the patient presents risk factors for the development of conduction abnormalities. ${ }^{6,7,78,79}$
Empiric antithrombotic therapy with aspirin $100 \mathrm{mg}$, lifelong, and clopidogrel $75 \mathrm{mg}$ for 3-6 months has been recommended for postoperative care, although any benefit of dual-platelet therapy has not yet been confirmed in clinical studies. A randomized controlled trial is currently underway to define optimal postoperative antithrombotic therapy after TAVR. ${ }^{80}$

\section{Complications}

The major complications after TAVR are stroke, vascular complications, conduction abnormalities, acute kidney injury, and aortic regurgitation. Additionally, a number of device-related complications such as valve embolization or malpositioning can occur during the procedure.

\section{Vascular complications}

Vascular complications are one of the most common complications after TAVR, occurring in $11.7 \%$ of cases. ${ }^{40}$ In the PARTNER Trial, dissection, perforation, and groin hematoma were the most frequent vascular complications, and were associated with a significantly higher mortality at 30 days and 1 year post-procedure. ${ }^{81}$ Serious complications such as aortic dissection or perforation are rare, occurring in $0.7 \%$ of cases. ${ }^{81}$ Periprocedural, they are usually related to catheter manipulation. Late aortic dissections might be due to ascending aneurysm formation. ${ }^{78}$ 
Risk factors include peripheral artery disease, severely calcified and tortuous vessels, circumferential calcifications, and an external sheath diameter larger than the minimal luminal diameter of the access vessel..$^{38,41,42}$

As is to be expected, vascular complications are significantly more frequent when a transarterial route is used compared with when a transapical approach is used $(3.4 \%$ vs $14.2 \%) .{ }^{40}$ When comparing the SAPIEN valve and CoreValve for the transarterial route, the risk of vascular damage is higher with the former $(22.3 \%$ vs $10.8 \%)$, which is probably related to the larger introducer sheaths used for the first-generation SAPIEN valve. ${ }^{40}$

As such, diligent preoperative imaging assessment and careful patient selection is crucial to minimize the risk of vascular injury. If vascular damage has occurred, balloon occlusion or stent implantation from the contralateral side is a fast and easy way to manage this type of complication, for which any interventionist should be prepared. ${ }^{78}$ Occasionally, surgical repair will be necessary. ${ }^{44}$

In future, smaller introducer sheaths and new vascular closure devices are likely to further reduce vascular morbidity after TAVR. ${ }^{38}$

\section{Neurologic events}

Possible causes for periprocedural cerebral infarctions in patients undergoing TAVR are embolization of debris from the aortic arch or aortic valve, episodes of hypotension or hemorrhagic stroke. ${ }^{21,82}$

A recent meta-analysis by Khatri et $\mathrm{al}^{40}$ on adverse events after TAVR reported an early stroke rate of $2.9 \%$. However, several studies have shown that $58 \%-77 \%$ of patients undergoing TAVR have small, silent cerebral infarctions detectable on magnetic resonance imaging with an incidence significantly higher than in patients undergoing SAVR ${ }^{83-86}$ At this time, it seems that these silent infarctions do not have negative impact on cognitive function or post-procedural health status. ${ }^{83,86}$ In contrast, if a clinically apparent neurologic event has occurred, mortality is increased. ${ }^{20,34,50,63}$

In part A of the PARTNER Trial, the 30-day prevalence of neurologic events was significantly higher after TAVR than after SAVR (5.5\% vs $2.4 \%, P=0.04)$, whereas the rate of major stroke showed a tendency toward higher prevalence after TAVR but did not reach significance (3.8\% vs $2.4 \%$, $P=0.2) .{ }^{17} \mathrm{~A}$ detailed analysis of neurologic events in the PARTNER Trial by Miller et $\mathrm{al}^{20}$ showed that there is an early phase after the procedure during which the risk of stroke is significantly increased with TAVR. ${ }^{20}$ During follow-up, the risk for neurologic events is primarily influenced by patient-related risk factors such as history of stroke, atrial fibrillation, and cerebrovascular disease, not by the procedure chosen. $^{82}$

There are studies suggesting that the transapical approach is associated with a reduced risk of stroke, ${ }^{49}$ but Khatri et al's meta-analysis could not show a significant difference in the prevalence of stroke between transapical and transarterial TAVR, nor between the SAPIEN valve and CoreValve. ${ }^{40}$

An increased risk of stroke is an important aspect when considering TAVR for lower-risk patients. Embolic protection devices might be a means to reduce intra-procedural embolic infarctions. Further clinical trials are necessary to improve TAVR device, patient, and access route selection with regard to stroke risk, and to define a postoperative antithrombotic therapy that minimizes embolization without increasing the risk of bleeding complications. ${ }^{20,82}$

\section{Pacemaker requirement and conduction abnormalities}

Permanent pacemaker implantation is required in $13.1 \%$ of patients undergoing TAVR. ${ }^{40}$ The most common indication is occurrence of AV block. ${ }^{66}$ Nuis et al reported that the overall prevalence of conduction abnormalities after CoreValve implantation is as high as 82 , with left-bundle branch block being the most frequent. ${ }^{87}$ In most cases, the conduction abnormality occurs during the procedure itself or within 24 hours, but cases of delayed heart block after up to 30 days have been described. ${ }^{7,87,88}$ Pacemaker requirement does not seem to affect long-term outcome, ${ }^{89}$ even though less improvement of left-ventricular function was observed in patients with new conduction defects. ${ }^{90}$

A number of risk factors for conduction abnormalities and permanent pacemaker requirement post-TAVR have been identified, including preexistent right-bundle branch block, preprocedural QRS complex length and AV delay, valve over-sizing, depth of implantation, and septal wall thickness. The relevance of aortic root calcification is controversial. ${ }^{6,66,78,79,88,91,92}$

Numerous studies have revealed that the risk of requiring a pacemaker post-procedure is significantly higher with the CoreValve than with the SAPIEN valve $(25.2 \%$ vs $5.0 \%) .{ }^{40}$ This is most likely to be due to the design of the CoreValve System. ${ }^{1,10,40,63-66,88,91,92}$

In view of the risk of delayed AV block, it has been recommended that patients be monitored for at least 24-48 hours post-procedure, perhaps for even longer after CoreValve implantation or if there are preexisting conduction abnormalities or any that are newly developed after TAVR. ${ }^{6,7,78,79}$ 


\section{Central aortic or paravalvular regurgitation}

Aortic regurgitation is a typical finding after TAVR and occurs in the majority of patients. In most cases, it is only mild. ${ }^{9,48}$ In part A of the PARTNER Trial, 11.8\% of patients undergoing TAVR had moderate to severe paravalvular regurgitation at 30 days, and $4.2 \%$ at 1 year. $^{17}$ Even though it remained stable or tended to improve during follow-up, even mild paravalvular regurgitation significantly increased mortality. The higher the degree of regurgitation, the higher the impact on mortality. ${ }^{17,19,21}$ The effect of aortic regurgitation on mortality has been confirmed by several other publications..$^{9,10,93}$

The extent of aortic annular calcification seems to be an important predictor of post-TAVR paravalvular regurgitation that can be anticipated on pre-procedural MDCT. ${ }^{45,94-96}$ Sherif et al identified the depth of implantation and the angle of the left-ventricular outflow tract to the ascending aorta as predictive of aortic regurgitation. ${ }^{97}$ Accurate sizing and positioning of the valve are important in preventing aortic regurgitation, as an undersized valve increases the risk of paravalvular regurgitation, while an oversized one might not fully expand, thus lead to central regurgitation. ${ }^{6,38} \mathrm{~A}$ higher incidence of aortic regurgitation with CoreValve has been discussed, but data on this question are conflicting. ${ }^{9,10,63,64}$ If relevant aortic regurgitation occurs immediately after the procedure, secondary balloon dilatation can decrease the degree of regurgitation, or a second transcatheter heart valve can be implanted "valve in valve." ",34,78

The incidence of paravalvular regurgitation after TAVR can probably be reduced by improved patient selection, preand intra-procedural imaging, and new transcatheter heart valve designs that have increased sealing capacities and repositioning features.

\section{Acute kidney injury}

Acute kidney injury requiring renal replacement therapy occurs in approximately $5 \%$ of patients. ${ }^{40}$ Khatri et al noted a higher rate in transapical versus transarterial SAPIEN valve implantations. ${ }^{40}$ In the setting of TAVR, acute kidney injury probably results from contrast medium, hypotension, and micro-embolization in patients with preexistent impaired renal function. ${ }^{44}$ Kidney injury is probably associated with a prolonged hospital stay and worse outcome, even though not all studies support this. Risk factors for acute kidney injury may include peripheral vascular disease, bleeding, blood transfusion, post-procedural aortic regurgitation, and the use of high amounts of contrast medium. . $, 8,34,98-101$

\section{Valve malpositioning, embolization, and other complications}

Malpositioning of the valve can lead to aortic regurgitation, coronary artery obstruction, injury to the aorta or to the mitral valve, arrhythmia or conduction disturbances, and embolization of the valve. ${ }^{44}$

In their meta-analysis on adverse events after TAVR, Khatri et al reported an overall rate of valve in valve implantation for implant failure of $2.2 \%$ with a higher rate among patients receiving a CoreValve implantation. The overall rate of conversion to open surgery was $1.2 \%{ }^{40}$

Valve embolization occurs in $1.3 \%$ of cases, ${ }^{40}$ usually due to malposition of the valve or a ventricular contraction ejecting the valve during deployment. As long as the valve remains in coaxial position within the aorta, hemodynamics can remain stable. If its position allows, the valve can be stabilized in its position by balloon dilatation or overstenting. Subsequently, a second attempt to implant a transcatheter heart valve can be made, or the procedure can be converted to open surgery. There are reports of embolized valves being left in place, but in most cases, the valve will have to be surgically removed. If the valve embolizes into the left ventricle, surgical removal is usually necessary. ${ }^{44,48,78,102}$ If valve misalignment results in severe aortic regurgitation, an attempt can be made to position a second transcatheter heart valve within the first one to reduce regurgitation. ${ }^{78,102}$ Transcatheter heart valves that allow recapturing and repositioning of the valve after deployment are currently undergoing clinical evaluation. ${ }^{69-71}$

Coronary artery obstruction can result from malpositioning of the valve, but the most likely cause is the displacement of a calcified leaflet over a coronary ostium or the embolization of debris into one of the coronary arteries. ${ }^{44}$ The risk is relatively low $(0.8 \%)$, with a somewhat higher likelihood with the SAPIEN valve than the CoreValve. ${ }^{6,40}$ Further, heavily calcified, elongated cusps and short and shallow sinuses of Valsalva have been reported to carry an increased risk of coronary obstruction. ${ }^{38,44}$ Diligent preoperative imaging assessment is crucial. A minimal distance of $10-14 \mathrm{~mm}$ between the annulus and the coronary ostia has been suggested to minimize the risk. Urgent percutaneous coronary intervention or coronary artery bypass is the only option if this complication occurs. ${ }^{44}$

Mitral valve injury can occur during transapical TAVR. It can also result if the ventricular end of the valve interferes with 
the movement of the mitral valve leaflets. Though rare, both acute and late mitral regurgitation have been described. ${ }^{44}$

Aortic root rupture is an infrequent, but catastrophic complication of TAVR. It causes immediate hemodynamic collapse and can only be treated by urgent surgical root replacement, which is associated with very poor outcome in this setting. ${ }^{7,44}$ Root rupture is more likely in patients with a small, heavily calcified aortic root. ${ }^{38}$ Aggressive balloon dilatation and undue over-sizing of the valve further increase the risk of annular rupture. ${ }^{7,44}$ Another differential diagnosis for unexplained hemodynamic deterioration after TAVR is cardiac tamponade due to cardiac perforation by one of the catheters or by a transvenous pacemaker. ${ }^{44}$

\section{Special patient subgroups}

Several subgroups of patients presenting for AVR - for example, patients with left-ventricular dysfunction - might especially benefit from SAVR as opposed to TAVR. Other conditions, such as bicuspid aortic valve, are currently considered contraindications for TAVR, even though feasibility of TAVR in these patients has been shown. This section provides an overview of the current evidence on TAVR in these special patient subsets.

\section{Concomitant mitral valve regurgitation}

The impact of moderate to severe mitral valve regurgitation on outcome after TAVR is controversial. While several authors have reported mitral regurgitation to be an independent predictor of mortality, ${ }^{34,35}$ other studies have not supported this observation. ${ }^{36,103}$ Although post-procedural mortality seems to be higher in patients with concomitant mitral valve regurgitation, functional status is generally improved..$^{36,103,104}$ Several authors have observed a significant reduction in mitral regurgitation in 30\%-55\% of patients. ${ }^{36,104,105}$

Currently, moderate and severe mitral regurgitation should not be considered a contraindication for TAVR. ${ }^{103}$ Concomitant or secondary mitral valve clipping is feasible, even though there is conflicting data on whether this approach can improve mortality and functional status. ${ }^{106,107}$

\section{Bicuspid aortic valve}

A bicuspid aortic valve is considered a relative contraindication for $\mathrm{TAVR}^{3}$ because a higher risk of malpositioning, paravalvular leakage, or incomplete expansion is assumed. ${ }^{108}$ Two small case series - one by Himbert et al ${ }^{109}$ and the other by Wijesinghe et al ${ }^{108}$ - have been published on TAVR with the CoreValve and SAPIEN valve in patients with bicuspid aortic valve. Though results were comparable with the current data on the outcome of TAVR, several patients had moderate paravalvular leakage, and two procedures had to be converted to open surgery. ${ }^{108,109}$ TAVR in patients with bicuspid valve is feasible, but careful patient selection and diligent sizing and positioning are very important. In particular, in patients with concomitant aortic root or ascending aortic dilatation, stable positioning of the valve might be difficult. ${ }^{108}$

\section{Patients with previous cardiac surgery}

The risk of reoperation after previous cardiac surgery is considered high. Therefore, TAVR was expected to be a promising alternative for patients who need AVR after previous surgery. ${ }^{110}$ Interestingly, two recent comparative retrospective studies reported that both treatment options provide good, comparable results. ${ }^{11,112}$ Wilbring et al ${ }^{111}$ observed that, despite a different pattern of postoperative complication, overall outcome did not differ significantly. ${ }^{111}$ Likewise, the PARTNER Trial surprisingly indicated that patients undergoing reoperation did better with open surgery than with TAVR. ${ }^{17}$ Although previous cardiac surgery represents an additional risk factor that must be considered, reoperation alone should not constitute an indication for an interventional approach. ${ }^{112}$

\section{Left-ventricular dysfunction}

Left-ventricular dysfunction is an important risk factor in patients undergoing SAVR. Patients with impaired LVEF could therefore be a subgroup that might benefit from TAVR. ${ }^{47}$

Several authors have addressed the outcome of patients with left-ventricular dysfunction undergoing TAVR. Fraccaro et al found a significantly higher early and late mortality in patients with low LVEF. ${ }^{113}$ Ewe et al did not note a difference in mortality, but the rate of combined major adverse events was higher in patients with an LVEF lower than $50 \% .{ }^{114}$ In contrast, both studies observed a significant improvement in LVEF after the procedure. ${ }^{113,114}$ In a study by van der Boon et al, survival did not differ at all between patients with normal and reduced LVEF. ${ }^{115}$

When comparing the outcome of patients with an ejection fraction below 50\% undergoing TAVR or SAVR, Clavel et al $^{116}$ observed no difference in risk-adjusted 30-day mortality, but patients undergoing TAVR had significantly better LVEF recovery. ${ }^{47,116}$ Bauer et al reported similar findings in a small comparative echocardiographic study. ${ }^{117}$

Although a debated issue, patients with impaired leftventricular function probably have an increased periprocedural risk compared with patients with normal left-ventricular 
function. ${ }^{113,114}$ However, LVEF seems to improve significantly after TAVR. ${ }^{113,114,116}$ Even though no benefit with regard to short-term mortality could be shown in comparison with SAVR, patients with low LVEF undergoing TAVR could benefit from a significantly better recovery of left-ventricular function. ${ }^{47,116}$

\section{Valve-in-valve procedures}

Transcatheter heart valves have been successfully implanted in failing bioprostheses or annuloplasty rings in all valve positions. ${ }^{47,118-123}$

Implanting a second transcatheter heart valve in a malpositioned or regurgitant transcatheter heart valve is a feasible bailout that has adequate results, but the resulting gradient is higher than in patients undergoing SAVR. ${ }^{78,102,121}$ SAPIEN valve implantations in CoreValve as well as CoreValve implantations in failing SAPIEN valves have been described. ${ }^{47}$

In patients with a failing surgical aortic bioprosthesis with high risk of reoperation, implanting a transcatheter heart valve within the bioprosthesis is a minimally invasive alternative to surgery. ${ }^{118,123}$ Both implantations in stented as well as in stent-less bioprostheses have been performed. ${ }^{118,119,122,123}$ The ring of the surgical valve allows excellent annular sealing for the transcatheter heart valve. Although the midterm outcome seems satisfactory, ${ }^{118,119,123}$ some specific issues have to be considered. Mean gradients are approximately $20 \mathrm{mmHg}$ higher than in a primary implanted transcatheter heart valve, and the long-term clinical effect of this observation is unknown. ${ }^{118,119,123}$ The risk of coronary artery obstruction seems to be significantly higher $(3.5 \%) .{ }^{119}$

Transapical implantation of a SAPIEN valve is a treatment option for a failing surgical mitral bioprosthesis or a mitral annuloplasty. Cheung et al reported favorable results in 23 high-risk patients, ${ }^{120}$ and similar positive results have been published by the Global Valve-in-Valve registry. ${ }^{119}$ The feasibility of valve-in-valve procedures in failing tricuspid bioprostheses and annuloplasty rings as well as pulmonary bioprostheses has been reported. ${ }^{118,124,125}$

Valve-in-valve procedures might be a promising approach for high-risk patients with failing surgical bioprostheses. The first data on valve-in-valve procedures in aortic position show satisfactory outcomes, but long-term results should be awaited. Data on valve-in-valve replacements in other valve positions are still limited. ${ }^{118}$

\section{Conclusion}

TAVR is assumed superior to medical treatment for inoperable patients with severe aortic stenosis and reasonable life expectancy. In high-risk patients, its midterm results are comparable, but not superior to, the results for SAVR. Concerning TAVR, a number of questions still have to be addressed, such as the incidence and clinical significance of stroke, paravalvular regurgitation, and conduction disturbances. New transcatheter devices abound; they might be able to prevent some of the complications associated with TAVR. The cost-effectiveness of TAVR compared with SAVR constitutes another relevant issue that is still unclear.

Importantly, despite the enthusiasm for broadening the indication for TAVR to lower-risk patients, it must be taken into account that we only have very limited data on long-term follow-up on transcatheter heart valves beyond 2 years, and valve durability is still uncertain. Future clinical trials and long-term follow-up will help define which patients will benefit from this rapidly developing approach.

\section{Disclosure}

The authors declare no conflicts of interest in this work.

\section{References}

1. Iung B, Baron G, Butchart EG, et al. A prospective survey of patients with valvular heart disease in Europe: The Euro Heart Survey on Valvular Heart Disease. Eur Heart J. 2003;24(13):1231-1243.

2. Stewart BF, Siscovick D, Lind BK, et al. Clinical factors associated with calcific aortic valve disease. Cardiovascular Health Study. J Am Coll Cardiol. 1997;29(3):630-634.

3. Vahanian A, Alfieri O, Andreotti F, et al; ESC Committee for Practice Guidelines (CPG); Joint Task Force on the Management of Valvular Heart Disease of the European Society of Cardiology (ESC); European Association for Cardio-Thoracic Surgery (EACTS). Guidelines on the management of valvular heart disease (version 2012): the Joint Task Force on the Management of Valvular Heart Disease of the European Society of Cardiology (ESC) and the European Association for Cardio-Thoracic Surgery (EACTS). Eur J Cardiothorac Surg. 2012;42(4):S1-S44.

4. Bridgewater B, Gummert J, Kinsman R, Walton P. The Fourth EACTS Adult Cardiac Surgical Database Report: Toward Global Benchmarking. Henley-on-Thames: Dendrite Clinical Systems; 2010.

5. Vahanian A, Baumgartner H, Bax J, et al; Task Force on the Management of Valvular Hearth Disease of the European Society of Cardiology; ESC Committee for Practice Guidelines. Guidelines on the management of valvular heart disease: The Task Force on the Management of Valvular Heart Disease of the European Society of Cardiology. Eur Heart J. 2007;28(2):230-268.

6. Webb JG, Wood DA. Current status of transcatheter aortic valve replacement. J Am Coll Cardiol. 2012;60(6):483-492.

7. Holmes DR, Mack MJ, Kaul S, et al; American Heart Association; American Society of Echocardiography; European Association for Cardio-Thoracic Surgery; Heart Failure Society of America; Mended Hearts; Society of Cardiovascular Anesthesiologists; Society of Cardiovascular Computed Tomography; Society for Cardiovascular Magnetic Resonance. 2012 ACCF/AATS/SCAI/STS expert consensus document on transcatheter aortic valve replacement: developed in collabration with the American Heart Association, American Society of Echocardiography, European Association for Cardio-Thoracic Surgery, Heart Failure Society of America, Mended Hearts, Society of Cardiovascular Anesthesiologists, Society of Cardiovascular Computed Tomography, and Society for Cardiovascular Magnetic Resonance. J Thorac Cardiovasc Surg. 2012;144(3):e29-e84. 
8. Sinning JM, Werner N, Nickenig G, Grube E. Transcatheter aortic valve implantation: the evidence. Heart. 2012;98 Suppl 4:iv65-iv72.

9. Gilard M, Eltchaninoff H, Iung B, et al; FRANCE 2 Investigators. Registry of transcatheter aortic-valve implantation in high-risk patients. N Engl J Med. 2012;366(18):1705-1715.

10. Moat NE, Ludman P, de Belder MA, et al. Long-term outcomes after transcatheter aortic valve implantation in high-risk patients with severe aortic stenosis: the UK TAVI (United Kingdom Transcatheter Aortic Valve Implantation) Registry. J Am Coll Cardiol. 2011;58(20):2130-2138.

11. Parolari A, Pesce LL, Trezzi M, et al. EuroSCORE performance in valve surgery: a meta-analysis. Ann Thorac Surg. 2010;89(3):787-793, 793, e1-e2.

12. Ussia GP, Barbanti M, Petronio AS, et al; CoreValve Italian Registry Investigators. Transcatheter aortic valve implantation: 3-year outcomes of self-expanding CoreValve prosthesis. Eur Heart J. 2012;33(8): 969-976.

13. Zahn R, Gerckens U, Grube E, et al; German Transcatheter Aortic Valve Interventions-Registry Investigators. Transcatheter aortic valve implantation: first results from a multi-centre real-world registry. Eur Heart J. 2011;32(2):198-204.

14. Thomas M, Schymik G, Walther T, et al. One-year outcomes of cohort 1 in the Edwards SAPIEN Aortic Bioprosthesis European Outcome (SOURCE) registry: the European registry of transcatheter aortic valve implantation using the Edwards SAPIEN valve. Circulation. 2011;124(4):425-433.

15. Wendler O, Walther T, Schroefel $\mathrm{H}$, et al; SOURCE investigators. Transapical aortic valve implantation: mid-term outcome from the SOURCE registry. Eur J Cardiothorac Surg. 2013;43(3):505-511; discussion 511-512.

16. Eurostat. The Life of Women and Men in Europe: A Statistical Portrait. 2008 ed. Luxembourg: Eurostat; 2008. Available from: http://epp. eurostat.ec.europa.eu/cache/ITY_OFFPUB/KS-80-07-135/EN/ KS-80-07-135-EN.PDF. Accessed June 4, 2013.

17. Svensson LG, Tuzcu M, Kapadia S, et al. A comprehensive review of the PARTNER trial. $J$ Thorac Cardiovasc Surg. 2013;145(Suppl 3): S11-S16.

18. Leon MB, Smith CR, Mack M, et al; PARTNER Trial Investigators. Transcatheter aortic-valve implantation for aortic stenosis in patients who cannot undergo surgery. $N$ Engl J Med. 2010;363(17):1597-1607.

19. Kodali SK, Williams MR, Smith CR, et al; PARTNER Trial Investigators. Two-year outcomes after transcatheter or surgical aorticvalve replacement. $N$ Engl J Med. 2012;366(18):1686-1695.

20. Miller DC, Blackstone EH, Mack MJ, et al; PARTNER Trial Investigators and Patients; PARTNER Stroke Substudy Writing Group and Executive Committee. Transcatheter (TAVR) versus surgical (AVR) aortic valve replacement: occurrence, hazard, risk factors, and consequences of neurologic events in the PARTNER trial. $J$ Thorac Cardiovasc Surg. 2012;143(4):832-843, e13.

21. Makkar RR, Fontana GP, Jilaihawi H, et al; PARTNER Trial Investigators. Transcatheter aortic-valve replacement for inoperable severe aortic stenosis. $N$ Engl J Med. 2012;366(18):1696-1704.

22. US Food and Drug Administration (FDA). FDA Executive Summary: P110021; Edwards SAPIEN ${ }^{\mathrm{TM}}$ Transcatheter Heart Valve. Silver Spring, MD: FDA; nd. Available from: http://www.fda.gov/downloads/ AdvisoryCommittees/CommitteesMeetingMaterials/MedicalDevices/ MedicalDevicesAdvisoryCommittee/CirculatorySystemDevicesPanel/ UCM307195.pdf. Accessed April 4, 2013.

23. Nielsen $\mathrm{HH}$, Klaaborg KE, Nissen $\mathrm{H}$, et al. A prospective, randomised trial of transapical transcatheter aortic valve implantation vs surgical aortic valve replacement in operable elderly patients with aortic stenosis: the STACCATO trial. EuroIntervention. 2012;8(3):383-389.

24. Sinning JM, Horack M, Grube E, et al. The impact of peripheral arterial disease on early outcome after transcatheter aortic valve implantation: results from the German Transcatheter Aortic Valve Interventions Registry. Am Heart J. 2012;164(1):102-110. e1.
25. Généreux P, Head SJ, Wood DA, et al. Transcatheter aortic valve implantation 10-year anniversary: review of current evidence and clinical implications. Eur Heart J. 2012;33(19):2388-2398.

26. Wendt D, Osswald BR, Kayser K, et al. Society of Thoracic Surgeons score is superior to the EuroSCORE determining mortality in high risk patients undergoing isolated aortic valve replacement. Ann Thorac Surg. 2009;88(2):468-474; discussion 474-475.

27. Ben-Dor I, Gaglia MA Jr, Barbash IM, et al. Comparison between Society of Thoracic Surgeons score and logistic EuroSCORE for predicting mortality in patients referred for transcatheter aortic valve implantation. Cardiovasc Revasc Med. 2011;12(6):345-349.

28. Watanabe Y, Hayashida K, Lefèvre T, et al. Is euroscore II better than EuroSCORE in predicting mortality after transcatheter aortic valve implantation? Catheter Cardiovasc Interv. 2013;81(6):1053-1060.

29. Schenk S, Fritzsche D, Atoui R, Koertke H, Koerfer R, Eitz T. EuroSCORE-predicted mortality and surgical judgment for interventional aortic valve replacement. J Heart Valve Dis. 2010;19(1):5-15.

30. Piazza N, Wenaweser P, van Gameren M, et al. Relationship between the logistic EuroSCORE and the Society of Thoracic Surgeons Predicted Risk of Mortality score in patients implanted with the CoreValve ReValving system - a Bern-Rotterdam Study. Am Heart J. 2010;159(2):323-329.

31. Goetzenich A, Deppe I, Schnöring H, et al. EuroScore 2 for identification of patients for transapical aortic valve replacement - a single center retrospective in 206 patients. J Cardiothorac Surg. 2012;7:89.

32. Dewey TM, Brown D, Ryan WH, Herbert MA, Prince SL, Mack MJ. Reliability of risk algorithms in predicting early and late operative outcomes in high-risk patients undergoing aortic valve replacement. J Thorac Cardiovasc Surg. 2008;135(1):180-187.

33. Piazza N, Lange R, Martucci G, Serruys PW. Patient selection for transcatheter aortic valve implantation: patient risk profile and anatomical selection criteria. Arch Cardiovasc Dis. 2012;105(3):165-173.

34. Tamburino C, Capodanno D, Ramondo A, et al. Incidence and predictors of early and late mortality after transcatheter aortic valve implantation in 663 patients with severe aortic stenosis. Circulation. 2011;123(3): 299-308.

35. Gotzmann M, Pljakic A, Bojara W, et al. Transcatheter aortic valve implantation in patients with severe symptomatic aortic valve stenosispredictors of mortality and poor treatment response. Am Heart J. 2011;162(2):238-245. e1.

36. D'Onofrio A, Gasparetto V, Napodano M, et al. Impact of preoperative mitral valve regurgitation on outcomes after transcatheter aortic valve implantation. Eur J Cardiothorac Surg. 2012;41(6):1271-1277.

37. Toggweiler S, Humphries KH, Lee M, et al. 5-year outcome after transcatheter aortic valve implantation. J Am Coll Cardiol. 2013;61(4): 413-419.

38. Achenbach S, Delgado V, Hausleiter J, Schoenhagen P, Min JK, Leipsic JA. SCCT expert consensus document on computed tomography imaging before transcatheter aortic valve implantation (TAVI)/ transcatheter aortic valve replacement (TAVR). J Cardiovasc Comput Tomogr. 2012;6(6):366-380.

39. Bloomfield GS, Gillam LD, Hahn RT, et al. A practical guide to multimodality imaging of transcatheter aortic valve replacement. JACC Cardiovasc Imaging. 2012;5(4):441-455.

40. Khatri PJ, Webb JG, Rodés-Cabau J, et al. Adverse effects associated with transcatheter aortic valve implantation: a meta-analysis of contemporary studies. Ann Intern Med. 2013;158(1):35-46.

41. Toggweiler S, Gurvitch R, Leipsic J, et al. Percutaneous aortic valve replacement: vascular outcomes with a fully percutaneous procedure. J Am Coll Cardiol. 2012;59(2):113-118.

42. Hayashida K, Lefèvre T, Chevalier B, et al. Transfemoral aortic valve implantation new criteria to predict vascular complications. JACC Cardiovasc Interv. 2011;4(8):851-858.

43. Kurra V, Lieber ML, Sola S, et al. Extent of thoracic aortic atheroma burden and long-term mortality after cardiothoracic surgery: a computed tomography study. JACC Cardiovasc Imaging. 2010;3(10): $1020-1029$. 
44. Masson JB, Kovac J, Schuler G, et al. Transcatheter aortic valve implantation: review of the nature, management, and avoidance of procedural complications. JACC Cardiovasc Interv. 2009;2(9): 811-820.

45. John D, Buellesfeld L, Yuecel S, et al. Correlation of Device landing zone calcification and acute procedural success in patients undergoing transcatheter aortic valve implantations with the selfexpanding CoreValve prosthesis. JACC Cardiovasc Interv. 2010;3(2): 233-243.

46. Mack MJ. Access for transcatheter aortic valve replacement: which is the preferred route? JACC Cardiovasc Interv. 2012;5(5):487-488.

47. Tang GHL, Lansman SL, Cohen M, et al. Transcatheter aortic valve replacement: current developments, ongoing issues, future outlook. Cardiol Rev. 2013;21(2):55-76.

48. Huffmyer J, Tashjian J, Raphael J, Jaeger JM. Management of the patient for transcatheter aortic valve implantation in the perioperative period. Semin Cardiothorac Vasc Anesth. 2012;16(1):25-40.

49. Bleiziffer S, Ruge H, Mazzitelli D, et al. Survival after transapical and transfemoral aortic valve implantation: talking about two different patient populations. J Thorac Cardiovasc Surg. 2009;138(5): 1073-1080.

50. Eggebrecht H, Schmermund A, Voigtländer T, Kahlert P, Erbel R, Mehta RH. Risk of stroke after transcatheter aortic valve implantation (TAVI): a meta-analysis of 10,037 published patients. Euro Intervention 2012;8(1):129-138.

51. Ramlawi B, Anaya-Ayala JE, Reardon MJ. Transcatheter aortic valve replacement (TAVR): access planning and strategies. Methodist Debakey Cardiovasc J. 2012;8(2):22-25.

52. Barbash IM, Dvir D, Ben-Dor I, et al. Impact of transapical aortic valve replacement on apical wall motion. J Am Soc Echocardiogr. 2013;26(3):255-260.

53. Johansson M, Nozohoor S, Kimblad PO, Harnek J, Olivecrona GK, Sjögren J. Transapical versus transfemoral aortic valve implantation: a comparison of survival and safety. Ann Thorac Surg. 2011;91(1): 57-63.

54. Ewe $\mathrm{SH}$, Delgado V, Ng AC, et al. Outcomes after transcatheter aortic valve implantation: transfemoral versus transapical approach. Ann Thorac Surg. 2011;92(4):1244-1251.

55. Bapat VN, Attia RQ, Thomas M. Distribution of calcium in the ascending aorta in patients undergoing transcatheter aortic valve implantation and its relevance to the transaortic approach. JACC Cardiovasc Interv. 2012;5(5):470-476.

56. Etienne PY, Papadatos S, El Khoury E, Pieters D, Price J, Glineur D. Transaortic transcatheter aortic valve implantation with the Edwards SAPIEN valve: feasibility, technical considerations, and clinical advantages. Ann Thorac Surg. 2011;92(2):746-748.

57. Bauernschmitt R, Schreiber C, Bleiziffer S, et al. Transcatheter aortic valve implantation through the ascending aorta: an alternative option for no-access patients. Heart Surg Forum. 2009;12(1):E63-E64.

58. Philipsen TE, Rodrigus IE, Claeys MJ, Bosmans JM. Alternative access in transcatheter aortic valve implantation: brachiocephalic artery access. Innovations (Phila). 2012;7(5):372-375

59. Caceres M, Braud R, Roselli EE. The axillary/subclavian artery access route for transcatheter aortic valve replacement: a systematic review of the literature. Ann Thorac Surg. 2012;93(3):1013-1018.

60. Petronio AS, De Carlo M, Bedogni F, et al. 2-year results of CoreValve implantation through the subclavian access: a propensity-matched comparison with the femoral access. J Am Coll Cardiol. 2012;60(6): 502-507

61. Guyton R, Block P, Thourani V, Lerakis S, Babaliaros V. Carotid artery access for transcatheter aortic valve replacement (TAVR). Catheter Cardiovasc Interv. Epub August 6, 2012.

62. Barbash IM, Ben-Dor I, Dvir D, et al. Graft-free surgical retroperitoneal vascular access as bail-out technique for failed percutaneous approach to transcatheter aortic valve replacement. Cardiovasc Revasc Med. 2013;14(1):23-26.
63. Nombela-Franco L, Ruel M, Radhakrishnan S, et al. Comparison of hemodynamic performance of self-expandable CoreValve versus balloon-expandable Edwards SAPIEN aortic valves inserted by catheter for aortic stenosis. Am J Cardiol. 2013;111(7):1026-1033.

64. Chieffo A, Buchanan GL, Van Mieghem NM, et al. Transcatheter aortic valve implantation with the Edwards SAPIEN versus the Medtronic CoreValve Revalving system devices: a multicenter collaborative study: the PRAGMATIC Plus Initiative (Pooled-RotterdAmMilano-Toulouse In Collaboration). J Am Coll Cardiol. 2013;61(8): 830-836.

65. Jilaihawi H, Chakravarty T, Weiss RE, Fontana GP, Forrester J, Makkar RR. Meta-analysis of complications in aortic valve replacement: comparison of Medtronic-Corevalve, Edwards-Sapien and surgical aortic valve replacement in 8,536 patients. Catheter Cardiovasc Interv. 2012;80(1):128-138.

66. Liang M, Devlin G, Pasupati S. The incidence of transcatheter aortic valve implantation-related heart block in self-expandable Medtronic CoreValve and balloon-expandable Edwards valves. J Invasive Cardiol. 2012;24(4):173-176.

67. Treede H, Mohr FW, Baldus S, et al. Transapical transcatheter aortic valve implantation using the JenaValve ${ }^{\mathrm{TM}}$ system: acute and 30-day results of the multicentre CE-mark study. Eur J Cardiothorac Surg. 2012;41(6):e131-e138.

68. Vikholm P, Schiller P, Johansson J, Hellgren L. A modified Glenn shunt improves haemodynamics in acute right ventricular failure in an experimental model. Eur J Cardiothorac Surg. 2013;43(3): 612-618.

69. Willson AB, Rodès-Cabau J, Wood DA, et al. Transcatheter aortic valve replacement with the St Jude Medical Portico valve: first-in-human experience. J Am Coll Cardiol. 2012;60(7):581-586.

70. Bijuklic K, Tuebler T, Reichenspurner H, et al. Midterm stability and hemodynamic performance of a transfemorally implantable nonmetallic, retrievable, and repositionable aortic valve in patients with severe aortic stenosis. Up to 2-year follow-up of the direct-flow medical valve: a pilot study. Circ Cardiovasc Interv. 2011;4(6):595-601.

71. Gooley R, Lockwood S, Antonis P, Meredith IT. The SADRA Lotus Valve System: a fully repositionable, retrievable prosthesis. Minerva Cardioangiol. 2013;61(1):45-52.

72. Falk V, Walther T, Schwammenthal E, et al. Transapical aortic valve implantation with a self-expanding anatomically oriented valve. Eur Heart J. 2011;32(7):878-887.

73. Binder RK, Schäfer U, Kuck KH, et al. Transcatheter aortic valve replacement with a new self-expanding transcatheter heart valve and motorized delivery system. JACC Cardiovasc Interv. 2013;6(3): 301-307.

74. Binder RK, Rodés-Cabau J, Wood DA, et al. Transcatheter aortic valve replacement with the SAPIEN 3: a new balloon-expandable transcatheter heart valve. JACC Cardiovasc Interv. 2013;6(3): 293-300.

75. Yamamoto M, Meguro K, Mouillet G, et al. Effect of local anesthetic management with conscious sedation in patients undergoing transcatheter aortic valve implantation. Am J Cardiol. 2013;111(1):94-99.

76. Willson A, Toggweiler S, Webb JG. Transfemoral aortic valve replacement with the SAPIEN XT valve: step-by-step. Semin Thorac Cardiovasc Surg. 2011;23(1):51-54.

77. Walther T, Dewey T, Borger MA, et al. Transapical aortic valve implantation: step by step. Ann Thorac Surg. 2009;87(1):276-283.

78. Stortecky S, Buellesfeld L, Wenaweser P, Windecker S. Transcatheter aortic valve implantation: the procedure. Heart. 2012;98 Suppl 4: iv44-iv51.

79. Piazza N, Nuis RJ, Tzikas A, et al. Persistent conduction abnormalities and requirements for pacemaking six months after transcatheter aortic valve implantation. EuroIntervention. 2010;6(4):475-484.

80. Lynch DR Jr, Dantzler D, Robbins M, Zhao D. Considerations in antithrombotic therapy among patients undergoing transcatheter aortic valve implantation. J Thromb Thrombolysis. 2013;35(4):476-482. 
81. Généreux P, Webb JG, Svensson LG, et al; PARTNER Trial Investigators. Vascular complications after transcatheter aortic valve replacement: insights from the PARTNER (Placement of AoRTic TraNscathetER Valve) trial. J Am Coll Cardiol. 2012;60(12):1043-1052.

82. Kahlert P, Al-Rashid F, Plicht B, et al. Incidence, predictors, origin and prevention of early and late neurological events after transcatheter aortic valve implantation (TAVI): a comprehensive review of current data. J Thromb Thrombolysis. 2013;35(4):436-449.

83. Fairbairn TA, Mather AN, Bijsterveld P, et al. Diffusion-weighted MRI determined cerebral embolic infarction following transcatheter aortic valve implantation: assessment of predictive risk factors and the relationship to subsequent health status. Heart. 2012;98(1):18-23.

84. Astarci P, Glineur D, Kefer J, et al. Magnetic resonance imaging evaluation of cerebral embolization during percutaneous aortic valve implantation: comparison of transfemoral and trans-apical approaches using Edwards Sapiens valve. Eur J Cardiothorac Surg. 2011;40(2): 475-479.

85. Arnold M, Schulz-Heise S, Achenbach S, et al. Embolic cerebral insults after transapical aortic valve implantation detected by magnetic resonance imaging. JACC Cardiovasc Interv. 2010;3(11): $1126-1132$.

86. Knipp SC, Kahlert P, Jokisch D, et al. Cognitive function after transapical aortic valve implantation: a single-centre study with 3-month follow-up. Interact Cardiovasc Thorac Surg. 2013;16(2): 116-122.

87. Nuis RJ, Van Mieghem NM, Schultz CJ, et al. Timing and potential mechanisms of new conduction abnormalities during the implantation of the Medtronic CoreValve System in patients with aortic stenosis. Eur Heart J. 2011;32(16):2067-2074.

88. Erkapic D, Kim WK, Weber M, et al. Electrocardiographic and further predictors for permanent pacemaker requirement after transcatheter aortic valve implantation. Europace. 2010;12(8):1188-1190.

89. Buellesfeld L, Stortecky S, Heg D, et al. Impact of permanent pacemaker implantation on clinical outcome among patients undergoing transcatheter aortic valve implantation. $J$ Am Coll Cardiol. 2012;60(6):493-501.

90. Hoffmann R, Herpertz R, Lotfipour S, et al. Impact of a new conduction defect after transcatheter aortic valve implantation on left ventricular function. JACC Cardiovasc Interv. 2012;5(12):1257-1263.

91. Aktug Ö, Dohmen G, Brehmer K, et al. Incidence and predictors of left bundle branch block after transcatheter aortic valve implantation. Int $J$ Cardiol. 2012;160(1):26-30.

92. Koos R, Mahnken AH, Aktug O, et al. Electrocardiographic and imaging predictors for permanent pacemaker requirement after transcatheter aortic valve implantation. J Heart Valve Dis. 2011; 20(1): 83-90.

93. Hayashida K, Lefèvre T, Chevalier B, et al. Impact of post-procedural aortic regurgitation on mortality after transcatheter aortic valve implantation. JACC Cardiovasc Interv. 2012;5(12):1247-1256.

94. Haensig M, Lehmkuhl L, Rastan AJ, et al. Aortic valve calcium scoring is a predictor of significant paravalvular aortic insufficiency in transapical-aortic valve implantation. Eur J Cardiothorac Surg. 2012;41(6):1234-1241.

95. Marwan M, Achenbach S, Ensminger SM, et al. CT predictors of postprocedural aortic regurgitation in patients referred for transcatheter aortic valve implantation: an analysis of 105 patients. Int J Cardiovasc Imaging. Epub February 19, 2013.

96. Koos R, Mahnken AH, Dohmen G, et al. Association of aortic valve calcification severity with the degree of aortic regurgitation after transcatheter aortic valve implantation. Int J Cardiol. 2011;150(2): $142-145$.

97. Sherif MA, Abdel-Wahab M, Stöcker B, et al. Anatomic and procedural predictors of paravalvular aortic regurgitation after implantation of the Medtronic CoreValve bioprosthesis. J Am Coll Cardiol. 2010;56(20):1623-1629.
98. Généreux P, Kodali SK, Green P, et al. Incidence and effect of acute kidney injury after transcatheter aortic valve replacement using the new valve academic research consortium criteria. Am J Cardiol. 2013;111(1):100-105.

99. Sinning JM, Ghanem A, Steinhäuser H, et al. Renal function as predictor of mortality in patients after percutaneous transcatheter aortic valve implantation. JACC Cardiovasc Interv. 2010;3(11): $1141-1149$.

100. Madershahian N, Scherner M, Liakopoulos O, et al. Renal impairment and transapical aortic valve implantation: impact of contrast medium dose on kidney function and survival. Eur J Cardiothorac Surg. 2012;41(6):1225-1232.

101. Wessely M, Rau S, Lange P, et al. Chronic kidney disease is not associated with a higher risk for mortality or acute kidney injury in transcatheter aortic valve implantation. Nephrol Dial Transplant. 2012;27(9):3502-3508.

102. Ussia GP, Barbanti M, Immè S, et al. Management of implant failure during transcatheter aortic valve implantation. Catheter Cardiovasc Interv. 2010;76(3):440-449.

103. Hutter A, Bleiziffer S, Richter V, et al. Transcatheter aortic valve implantation in patients with concomitant mitral and tricuspid regurgitation. Ann Thorac Surg. 2013;95(1):77-84.

104. Toggweiler S, Boone RH, Rodés-Cabau J, et al. Transcatheter aortic valve replacement: outcomes of patients with moderate or severe mitral regurgitation. J Am Coll Cardiol. 2012;59(23):2068-2074.

105. Giordana F, Capriolo M, Frea S, et al. Impact of TAVI on mitral regurgitation: a prospective echocardiographic study. Echocardiography. 2013;30(3):250-257.

106. Rudolph V, Schirmer J, Franzen O, et al. Bivalvular transcatheter treatment of high-surgical-risk patients with coexisting severe aortic stenosis and significant mitral regurgitation. Int $J$ Cardiol. Epub March 27, 2012.

107. Kische S, D'Ancona G, Paranskaya L, et al. Staged total percutaneous treatment of aortic valve pathology and mitral regurgitation: institutional experience. Catheter Cardiovasc Interv. Epub January 29, 2013.

108. Wijesinghe N, Ye J, Rodés-Cabau J, et al. Transcatheter aortic valve implantation in patients with bicuspid aortic valve stenosis. JACC Cardiovasc Interv. 2010;3(11):1122-1125.

109. Himbert D, Pontnau F, Messika-Zeitoun D, et al. Feasibility and outcomes of transcatheter aortic valve implantation in high-risk patients with stenotic bicuspid aortic valves. Am J Cardiol. 2012; 110(6):877-883.

110. D'Onofrio A, Rubino P, Fusari M, et al; on behalf of the I-TA investigators. Impact of previous cardiac operations on patients undergoing transapical aortic valve implantation: results from the Italian Registry of Transapical Aortic Valve Implantation. Eur $J$ Cardiothorac Surg. 2012;42(3):480-485.

111. Wilbring M, Tugtekin SM, Alexiou K, Simonis G, Matschke K, Kappert U. Transapical transcatheter aortic valve implantation vs conventional aortic valve replacement in high-risk patients with previous cardiac surgery: a propensity-score analysis. Eur J Cardiothorac Surg. Epub January 22, 2013.

112. Stortecky S, Brinks H, Wenaweser P, et al. Transcatheter aortic valve implantation or surgical aortic valve replacement as redo procedure after prior coronary artery bypass grafting. Ann Thorac Surg. 2011;92(4):1324-1331.

113. Fraccaro C, Al-Lamee R, Tarantini G, et al. Transcatheter aortic valve implantation in patients with severe left ventricular dysfunction: immediate and mid-term results, a multicenter study. Circ Cardiovasc Interv. 2012;5(2):253-260.

114. Ewe SH, Ajmone Marsan N, Pepi M, et al. Impact of left ventricular systolic function on clinical and echocardiographic outcomes following transcatheter aortic valve implantation for severe aortic stenosis. Am Heart J. 2010;160(6):1113-1120. 
115. van der Boon RM, Nuis RJ, Van Mieghem NM, et al. Clinical outcome following Transcatheter Aortic Valve Implantation in patients with impaired left ventricular systolic function. Catheter Cardiovasc Interv. 2012;79(5):702-710.

116. Clavel MA, Webb JG, Rodés-Cabau J, et al. Comparison between transcatheter and surgical prosthetic valve implantation in patients with severe aortic stenosis and reduced left ventricular ejection fraction. Circulation. 2010;122(19):1928-1936.

117. Bauer F, Coutant V, Bernard M, et al. Patients with severe aortic stenosis and reduced ejection fraction: earlier recovery of left ventricular systolic function after transcatheter aortic valve implantation compared with surgical valve replacement. Echocardiography. Epub March 12, 2013.

118. Mylotte D, Lange R, Martucci G, Piazza N. Transcatheter heart valve implantation for failing surgical bioprostheses: technical considerations and evidence for valve-in-valve procedures. Heart. Epub March 6, 2013.

119. Dvir D, Webb J, Brecker S, et al. Transcatheter aortic valve replacement for degenerative bioprosthetic surgical valves: results from the global valve-in-valve registry. Circulation. 2012;126(19):2335-2344.

120. Cheung A, Webb JG, Barbanti M, et al. 5-year experience with transcatheter transapical mitral valve-in-valve implantation for bioprosthetic valve dysfunction. J Am Coll Cardiol. 2013;61(17): 1759-1766.

121. Toggweiler S, Wood DA, Rodés-Cabau J, et al. Transcatheter valve-invalve implantation for failed balloon-expandable transcatheter aortic valves. JACC Cardiovasc Interv. 2012;5(5):571-577.
122. Finch J, Roussin I, Pepper J. Failing stentless aortic valves: redo aortic root replacement or valve in a valve? Eur J Cardiothorac Surg. 2013;43(3):495-504.

123. Piazza N, Bleiziffer S, Brockmann G, et al. Transcatheter aortic valve implantation for failing surgical aortic bioprosthetic valve: from concept to clinical application and evaluation (part 2). JACC Cardiovasc Interv. 2011;4(7):733-742.

124. Gaia DF, Palma JH, de Souza JA, Buffolo E. Tricuspid transcatheter valve-in-valve: an alternative for high-risk patients. Eur J Cardiothorac Surg. 2012;41(3):696-698.

125. Chowdhury SM, Hijazi ZM, Rhodes J, et al. Early echocardiographic changes after percutaneous implantation of the edwards SAPIEN transcatheter heart valve in the pulmonary position. Echocardiography. Epub February 22, 2013.

126. D'Onofrio A, Rubino P, Fusari M, et al. Clinical and hemodynamic outcomes of "all-comers" undergoing transapical aortic valve implantation: results from the Italian Registry of Trans-Apical Aortic Valve Implantation (I-TA). J Thorac Cardiovasc Surg. 2011;142(4): 768-775.

127. Smith CR, Leon MB, Mack MJ, et al; PARTNER Trial Investigators Transcatheter versus surgical aortic-valve replacement in high-risk patients. N Engl J Med. 2011;364(23):2187-2198.
Research Reports in Clinical Cardiology

\section{Publish your work in this journal}

Research Reports in Clinical Cardiology is an international, peerreviewed, open access journal publishing original research, reports, editorials, reviews and commentaries on all areas of cardiology in the clinic and laboratory. The manuscript management system is completely online and includes a very quick and fair peer-review system.

\section{Dovepress}

Visit http://www.dovepress.com/testimonials.php to read real quotes from published authors. 